\title{
Prevalence of metabolic syndrome in scholars from Bucaramanga, Colombia: a population-based study
} Cristina Villa-Roel*1,3, Adriana Buitrago1, Diana C Rodríguez ${ }^{1}$, Diana J Cano ${ }^{1}$, María P Martínez ${ }^{1}$, Paul A Camacho ${ }^{1}$, Álvaro J Ruiz ${ }^{2}$ and Álvaro E Durán ${ }^{1}$

\begin{abstract}
Address: ${ }^{1}$ Pediatric Research Area, Fundación Cardiovascular de Colombia, Floridablanca, Calle 155 A \# 23 - 58, Urbanización el Bosque/ Floridablanca/Santander, Colombia, ${ }^{2}$ Department of Clinical Epidemiology and Biostatistics, Pontificia Universidad Javeriana, Bogotá, Carrera 7 No. 40 - 62 Bogotá DC, Colombia and ${ }^{3}$ Department of Emergency Medicine, University of Alberta, 1G1.52 Walter C. Mackenzie Health Sciences Center, 8440 - 112 Street, Edmonton, Alberta, T6G 2B7, Canada

Email: Cristina Villa-Roel* - Cristina.villaroel@capitalhealth.ca; Adriana Buitrago - adriana.bl82@gmail.com; Diana C Rodríguez - dradianita82@gmail.com; Diana J Cano - dianacano@fcv.org; María P Martínez - mariapaulis@gmail.com; Paul A Camacho - paulcamacho@fcv.org; Álvaro J Ruiz - aruiz@javeriana.edu.co; Álvaro E Durán - alvaroduran@fcv.org

* Corresponding author
\end{abstract}

Published: 21 April 2009

BMC Pediatrics 2009, 9:28 doi:10.1 |86/|47|-2431-9-28
Received: II March 2009

Accepted: 21 April 2009

This article is available from: http://www.biomedcentral.com/I47I-243I/9/28

(c) 2009 Villa-Roel et al; licensee BioMed Central Ltd.

This is an Open Access article distributed under the terms of the Creative Commons Attribution License (http://creativecommons.org/licenses/by/2.0), which permits unrestricted use, distribution, and reproduction in any medium, provided the original work is properly cited.

\begin{abstract}
Background: Obesity and metabolic syndrome are strongly associated with type 2 diabetes mellitus and cardiovascular diseases, thus the increasing trend in their prevalence among children and adolescents from developing countries requires a further understanding of their epidemiology and determinants.

Methods and design: A cross-sectional study was designed to determine the prevalence of metabolic syndrome among 6-10 year-old children from Bucaramanga, Colombia. A two-stage random-cluster (neighborhoods, houses) sampling process was performed based on local city maps and local statistics. The study involves a domiciliary survey; including a comprehensive sociodemographic, nutritional and physical activity characterization of the children that participated in the study, followed by a complete clinical examination; including blood pressure, anthropometry, lipid profile determination, fasting glucose and insulin levels. The prevalence of metabolic syndrome will be determined using definitions and specific percentile cut-off points for this population. Finally, the association between components of metabolic syndrome and higher degrees of insulin resistance will be analyzed through a multivariable logistic regression model. This study protocol was designed in compliance with the Helsinki declaration and approved by the local ethics board. Consent was obtained from the children and their parents/guardians.

Discussion: A complete description of the environmental and non-environmental factors underlying the burden of metabolic syndrome in children from a developing country like Colombia will provide policy makers, health care providers and educators from similar settings with an opportunity to guide primary and secondary preventive initiatives at both individual and community levels. Moreover, this description may give an insight into the pathophysiological mechanisms mediating the development of cardio-metabolic diseases early in life.
\end{abstract}




\section{Background}

Cardiovascular diseases (CVD) are one of the major problems in public health and are responsible for more than $50 \%$ of all mortality in the western world [1]. CVD are not exclusive to developed countries. Nowadays, men, women and children from developing countries are recognized as populations at risk of developing CVD due to the nutritional, demographic, epidemiological and socioeconomic transitions they have been facing during the past few decades.

Persistent malnutrition, sedentary lifestyle and obesity have been associated with alterations in the processes that regulate the control of blood pressure and the action of insulin on the metabolism of carbohydrates and lipids. There is an urgent call to strategize health policies and intervention programs to tackle the factors influencing this phenomenon in the early stages of life [2]. Together these factors are known as the metabolic syndrome (MS) [3], a condition that is strongly associated with the development of type 2 diabetes mellitus (DM) and CVD [4-7].

\section{Metabolic Syndrome in children}

Similar to adults, the prevalence of overweight and obese children and adolescents has shown an increasing trend [8-11]. Moreover, the association between obesity and the clustering of CVD risk factors early in life, and their persistence during adulthood has been explored by several groups [12-19]. Data pertaining to MS in children are scarce. This is in part due to the lack of a consensus on the definition of MS in this population and to the inclusion of children together with adolescents in most studies [20]. Furthermore, most of the epidemiological characteristics of MS in children have been studied in developed countries and little is known about this condition and its association with insulin resistance (IR) in children from developing countries. Several definitions for MS in children have been postulated [21-24]; however, the cut-off points for each of its components, as well as their diagnostic and prognostic validity, remain unclear [20]. More recent definitions of MS in children have tended to be age and ethnic-specific and to take into account developmental changes during the growing process $[25,26]$. It is well recognized that IR constitutes a crucial element linking the presence of cardiovascular risk factors and the development of CVD [27]. The Homeostasis Model Assessment (HOMA) index is one of the surrogate methods used for the evaluation of insulin sensitivity, and has proven to be strongly associated with endothelial dysfunction and the future development of DM and CVD [28].

Both, genetic and environmental factors interact and contribute to the burden of MS; however, environmental factors seem to play a predominant role. The most commonly described factors involved in the development of MS include: rapid nutritional transition, rural-to-urban migration, adoption of a sedentary lifestyle and maternalfetal related conditions [29]. There is now a general agreement that all these elements need to be carefully analyzed from local, culturally-sensitive and cost-effective perspectives with the final goal of establishing globally acceptable criteria for the early detection and intervention of MS. Moreover, strategies for the management of MS require the integration of multiple stakeholders such as government and nongovernmental policy makers, interdisciplinary health care providers and educational organizations.

The aim of this study is to determine the prevalence of MS in 6-10 year-old children from Bucaramanga, Colombia, based on sex and age adjusted percentile cut-off points for the different anthropometric, hemodynamic and biochemical parameters in this population. The secondary objectives of this study involve a description of the children's socio-demographic, nutritional and physical activity profile and the analysis of the association between the proposed components of MS and higher degrees of IR (using the HOMA index).

\section{Methods and design Design}

Cross-sectional and population-based study.

\section{Eligibility}

Children, 6-10 years old, who had lived in Bucaramanga, Colombia during the last 12 months were eligible. Those with a history of menarche and/or Tanner stage $\geq 2$, prior diagnosis of DM or other endocrine disorder; and/or previous treatment with hormones or steroids (except for sodium levothyroxine) during the last month were excluded.

\section{Sample size and method of recruitment}

A sample size of 1282 children was calculated from the total 6-10 year-old population from Bucaramanga $(\mathrm{N}=$ $40,793)$, Colombia. We based this calculation on an expected prevalence of MS in children of $8 \%$, an absolute precision between $1-5 \%$, a confidence level of $95 \%$ and a design effect of 2 . Using local city maps and local statistics [30,31], a two-stage sampling process was performed (Figure 1). In the first stage, a random selection of neighborhoods that had at least 50 children (clusters) was made. In the second stage, a random selection of a maximum of 50 houses in each neighborhood was completed. All children who fulfilled the inclusion criteria in each of the selected houses were invited to participate in the study.

\section{Data collection}

During 16 months (July 2006-October 2007), a domiciliary survey for socio-demographic, nutritional and physical activity data collection was administered to the 


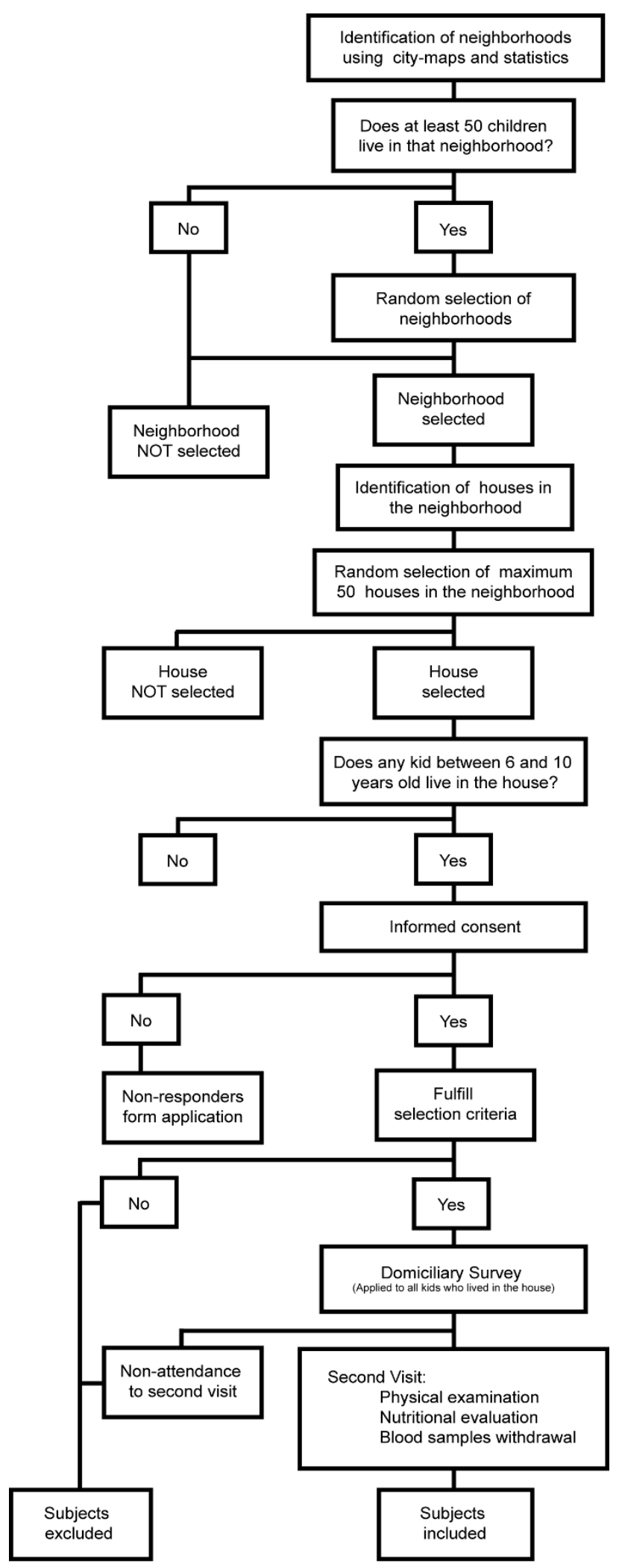

Figure I

Study flow. 
children's caregivers by trained research assistants. On a second visit, a complete physical examination (including blood pressure and anthropometric measurements) and blood withdrawal (for the determination of lipid profile, fasting glucose and insulin levels), were performed by trained physicians and nutritionists at the "Fundación Cardiovascular de Colombia" (FCV).

\section{Study variables}

Demographic factors such as age, sex, ethnicity (visually assessed by a trained research assistant), educational level, and socioeconomic status were collected. Health care availability was confirmed by checking children's health insurance cards. Children's and family history were obtained directly from their caregivers and whenever possible confirmed by legal documents (e.g. birth certificate and medical records).

Smoking status was categorized as active and passive exposure to cigarettes. Nutritional habits were collected through a 24 hour recall. Physical activity was assessed by asking the time (hours per day) the children spent doing several activities such as sleeping, studying (both, at school and home), doing moderate physical activity (e.g. walking, biking, skating, playing in a pool, gymnastics, ballet or dancing; playing at home or in a park; playing an instrument), doing vigorous physical activities (running, carrying heavy objects, biking and skating with considerable speed, practicing competitive sports or dancing, playing football, basketball or volleyball) and spending in front of screens (e.g. television, computers or videogames), during one day of the week and weekend. Physical or neurological deficits were recorded if they were referred by the caregivers.

Children's heart and respiratory rates were measured in a comfortable condition after a 10-min resting period. Blood pressure was measured three times (with 5 minutes between each) with their arm supported at the level of the heart and seated quietly, using a automated blood pressure monitor (Dinamap Pro 100; GE Medical Systems Information Technologies, Inc., Milwaukee, Wisconsin) and following the recommendations of the National High Blood Pressure Education Program (NHBPEP) Working Group on Children and Adolescents [32]. Percentiles of blood pressure according to the percentiles of weight/age were determined [33,34].

Anthropometric variables (weight, height, skin-folds, waist and hip circumferences) were measured in duplicate by two independent nutritionists, in the morning after urine elimination, with the child using light clothing and no shoes [34,35]. The Body Mass Index (BMI) was calculated according to the CDC recommendations [36,37].
Percentiles of weight/age and of BMI were also determined [38].

Under fasting conditions (at least 10 hours), blood samples were taken from the antecubital vein. Glycemia and Lipid Profile were immediately quantified by a routine colorimetric method (Biosystems BTS-303 Photometric, Spain). Part of the samples were stored at $-80^{\circ} \mathrm{C}$, and insulin determinations assessed by electrochemiluminescence immunoassay "ECLIA" technique (Roche Elecsys 1010/ 2010 and MODULAR ANALYTICS E170 (Elecsys module) immunoassay analyzers) in one assay at the end of the study. The HOMA Index was obtained from a mathematical model using the following formula: $\left(22.5 /\left[\mathrm{I}_{\mathrm{F}}{ }^{*} \mathrm{G}_{\mathrm{F}}\right]\right)$ $\left(\mathrm{I}_{\mathrm{F}}\right.$ : Fasting insulin levels in $\mathrm{IU} / \mathrm{L}, \mathrm{G}_{\mathrm{F}}$ : Fasting glucose levels in $\mathrm{mmol} / \mathrm{L}$ ) [39].

\section{Data quality and statistical analyses}

Study forms were reviewed to ensure they were complete before data entry. Data were entered by duplicate into Microsoft Excel spreadsheets (Microsoft Corp., Redmond, Wash.) and compared using Epi-Info 2000. Any discrepancy was corrected using the original study forms. The phase of data analysis is now in progress. Bivariable analyses for dichotomous and continuous variables will be performed by chi-square test, t-tests or Mann-Whitney tests, respectively. The association between components of MS and the higher quintile of the HOMA index will be analyzed through a logistic regression model considering adjustments by clustering effect. All p-values will be twotailed, with $\mathrm{p}<0.01$ considered statistically significant. Data will be analyzed using Stata Statistical Software ${ }^{\circledR}$ : Release 10.0. (College Station, TX: Stata Corporation). Nutritional data will be analyzed using the software Ceres version 1.02 "FAO 1998" (adapted version for Latin America and the Caribbean).

\section{Logistical considerations}

During the recruitment phase we faced several security issues. In order to assure that the sampling strategies were not violated we asked for support from community leaders and the local police department. We organized several promotion and health campaigns in tolerance zones in order to explain the purposes of the study, introduce the study personnel to the community and to agree on areas in which the survey and clinical examinations could be performed.

\section{Ethical considerations}

The study protocol was designed in compliance with the Helsinki declaration and approved by the Research Ethics Board from the FCV. Consent was obtained from all participants and from their parents/guardians. Additionally, all children gave their verbal assent. 


\section{Discussion}

Environmental and non-environmental factors underlying MS in developing countries could be different to those described in other populations. Population-based research on this topic needs to take in to account the peculiarities and limited resources in these settings in order to preserve methodological rigor. Despite facing some security and logistical problems, a rigorous sampling method, data collection and management were completed during the first phase of this study. To our knowledge, this project constitutes the first population-based study of cardiovascular risk factors in Colombian scholars.

We strongly believe that the results of this study will help establish globally acceptable criteria for the early detection and intervention of MS in children. Moreover, they will provide policy makers, health care providers and educators from a developing country like Colombia with an opportunity to guide primary and secondary preventive initiatives at individual and community levels.

\section{Abbreviations}

BMI: denotes body mass index; CVD: cardiovascular diseases; DM: diabetes mellitus; FCV: Fundación Cardiovascular de Colombia; HOMA: homeostasis model assessment; MS: metabolic syndrome; NHBPEP: National High Blood Pressure Education Program

\section{Competing interests}

The authors declare that they have no competing interests.

\section{Authors' contributions}

CVR was responsible for the study design, coordinated the study conduct and will be responsible for the analyses and manuscript production. AB, DCR and DJC coordinated the study personnel, the recruitment phase and were responsible for data management. MPM and PAC contributed to the study design and to the submission for funding. Finally, AJR and AED participated in the study design and supported the group in the submission for funding.

\section{Acknowledgements}

The authors of this protocol received a grant from the Colombian institute for the development of science and technology (COLCIENCIAS 656604 I8215) to support the study. The research team would like to thank Dr. Juan Pablo Casas, Dr. Christian F. Rueda-Clausen, Dr. Walter Mosquera and Dr. Juan Gabriel Ruiz for their contributions during the study design and conduct; the Department of Pediatrics at the FCV and the Department of Clinical Epidemiology and Biostatistics at the Universidad Javeriana for their in-kind support of this project. Finally, we would like to express our gratitude to Dr. Jude Morton for her support in the style correction of this manuscript.

Preliminary results from this protocol have been presented at the Metabolic Syndrome and Endothelium, Pan American Course: Health Public implications, Bogotá, Colombia (March 28-29, 2007); $25^{\text {th }}$ National Pediatric Congress, Medellín, Colombia (June 13-16, 2007) and 22nd Cardiology and Cardiovascular Surgery Colombian Congress, Cartagena, Colombia (February 12th 2008 ).

\section{References}

I. Rosamond WD, Chambless LE, Folsom AR, Cooper LS, Conwill DE, Clegg L, Wang CH, Heiss G: Trends in the incidence of myocardial infarction and in mortality due to coronary heart disease, I 987 to 1994. N Engl J Med 1998, 339:86I-867.

2. Reddy KS: Cardiovascular diseases in the developing countries: dimensions, determinants, dynamics and directions for public health action. Public Health Nutr 2002, 5:231-237.

3. Grundy SM: Inflammation, hypertension, and the metabolic syndrome. JAMA 2003, 290:3000-3002.

4. Third Report of the National Cholesterol Education Program (NCEP) Expert Panel on Detection, Evaluation, and Treatment of High Blood Cholesterol in Adults (Adult Treatment Panel III) final report. Circulation 2002, I 06:3143-342I.

5. Chan JM, Rimm EB, Colditz GA, Stampfer MJ, Willett WC: Obesity, fat distribution, and weight gain as risk factors for clinical diabetes in men. Diabetes Care 1994, I 7:961-969.

6. Mensah GA, Mokdad AH, Ford E, Narayan KM, Giles WH, Vinicor F, Deedwania PC: Obesity, metabolic syndrome, and type 2 diabetes: emerging epidemics and their cardiovascular implications. Cardiol Clin 2004, 22:485-504.

7. Rexrode KM, Carey VJ, Hennekens CH, Walters EE, Colditz GA, Stampfer MJ, Willett WC, Manson JE: Abdominal adiposity and coronary heart disease in women. JAMA 1998, 280:1843-1848.

8. Wang Y, Monteiro C, Popkin BM: Trends of obesity and underweight in older children and adolescents in the United States, Brazil, China, and Russia. Am J Clin Nutr 2002, 75:971-977.

9. Uscategui Peñuela RM, Alvarez Uribe MC, Laguado Salinas I, Soler Terranova W, Martinez Maluendas L, Arias Arteaga R, Duque Jaramillo B, Perez Giraldo J, Camacho Perez JA: Cardiovascular risk factors in children and teenagers aged 6- 18 years old from Medellín (Colombia). An Pediatr (Barc) 2003, 58:4 I I-4I7.

10. Martorell R, Kettel KL, Hughes ML, Grummer-Strawn LM: Overweight and obesity in preschool children from developing countries. Int J Obes Relat Metab Disord 2000, 24:959-967.

II. de Onis M, Blossner M: Prevalence and trends of overweight among preschool children in developing countries. Am J Clin Nutr 2000, 72:1032-1039.

12. Vikram NK, Misra A, Pandey RM, Luthra K, Wasir JS, Dhingra V: Heterogeneous phenotypes of insulin resistance and its implications for defining metabolic syndrome in Asian Indian adolescents. Atherosclerosis 2006, 186:193-199.

13. Steinberger J, Daniels SR: Obesity, insulin resistance, diabetes, and cardiovascular risk in children: an American Heart Association scientific statement from the Atherosclerosis, Hypertension, and Obesity in the Young Committee (Council on Cardiovascular Disease in the Young) and the Diabetes Committee (Council on Nutrition, Physical Activity, and Metabolism). Circulation 2003, I07:1448-1453.

14. Smoak CG, Burke GL, Webber LS, Harsha DW, Srinivasan SR, Berenson GS: Relation of obesity to clustering of cardiovascular disease risk factors in children and young adults. The Bogalusa Heart Study. Am J Epidemiol 1987, I 25:364-372.

15. Li Y, Yang X, Zhai F, Piao J, Zhao W, Zhang J, Ma G: Childhood obesity and its health consequence in China. Obes Rev 2008, 9(Suppl I):82-86.

16. Li Y, Yang X, Zhai F, Kok FJ, Zhao W, Piao J, Zhang J, Cui Z, Ma G: Prevalence of the metabolic syndrome in Chinese adolescents. Br J Nutr 2008, 99:565-570.

17. Lee MS, Wahlqvist ML, Yu HL, Pan WH: Hyperuricemia and metabolic syndrome in Taiwanese children. Asia Pac J Clin Nutr 2007, I 6(Suppl 2):594-600.

18. Chu NF, Rimm EB, Wang DJ, Liou HS, Shieh SM: Clustering of cardiovascular disease risk factors among obese schoolchildren: the Taipei Children Heart Study. Am J Clin Nutr 1998, 67: I|4|-||46.

19. Bao W, Srinivasan SR, Wattigney WA, Berenson GS: Persistence of multiple cardiovascular risk clustering related to syndrome $X$ from childhood to young adulthood. The Bogalusa Heart Study. Arch Intern Med 1994, I 54: I842-1847. 
20. Ford ES, Li C: Defining the metabolic syndrome in children and adolescents: will the real definition please stand up? J Pediatr 2008, 152:160-164.

21. Rodriguez-Moran M, Salazar-Vazquez B, Violante R, GuerreroRomero F: Metabolic syndrome among children and adolescents aged I0-I8 years. Diabetes Care 2004, 27:25I6-25I7.

22. Lambert M, Paradis G, O'Loughlin J, Delvin EE, Hanley JA, Levy E: Insulin resistance syndrome in a representative sample of children and adolescents from Quebec, Canada. Int J Obes Relat Metab Disord 2004, 28:833-84I.

23. Cook S, Weitzman M, Auinger P, Nguyen M, Dietz WH: Prevalence of a metabolic syndrome phenotype in adolescents: findings from the third National Health and Nutrition Examination Survey, 1 988-1 994. Arch Pediatr Adolesc Med 2003, 157:821-827.

24. Balkau B, Charles MA: Comment on the provisional report from the WHO consultation. European Group for the Study of Insulin Resistance (EGIR). Diabet Med 1999, 16:442-443.

25. International Diabetes Federation: The IDF consensus worldwide definition of the metabolic syndrome. 2005 [http:// www.idf.org/webdata/docs/Mets definition children.pdf].

26. Zimmet P, Alberti KG, Kaufman F, Tajima N, Silink M, Arslanian S, Wong $G$, Bennett $P$, Shaw J, Caprio $S$ : The metabolic syndrome in children and adolescents - an IDF consensus report. Pediat Diabetes 2007, 8:299-306.

27. Razani B, Chakravarthy MV, Semenkovich CF: Insulin resistance and atherosclerosis. Endocrinol Metab Clin North Am 2008 37:603-21.

28. Cruz ML, Weigensberg MJ, Huang TT, Ball G, Shaibi GQ, Goran MI: The metabolic syndrome in overweight Hispanic youth and the role of insulin sensitivity. J Clin Endocrinol Metab 2004, 89:108-1I3.

29. Misra $A$, Khurana $L$ : Obesity and the metabolic syndrome in developing countries. J Clin Endocrinol Metab 2008, 93:S9-30.

30. DANE - Departamento Administrativo Nacional de Estadística: Censo General 2005. Perfil Bucaramanga - Santander. 2005 [http://www.dane.gov.co/files/censo2005/perfiles/santander/bucara manga.pdf].

31. Ministerio de la protección social: Situación de salud de Colombia. Indicadores básicos 2005. [http://www.minproteccionso cial.gov.co/VBeContent/NewsDetail.asp?ID=|5895\&IDCompany=3].

32. National High Blood Pressure Education Program Working Group on High Blood Pressure in Children and Adolescents: The fourth report on the diagnosis, evaluation, and treatment of high blood pressure in children and adolescents. Pediatrics 2004, I 1 4:555-576.

33. Blood Pressure Tables for Children and Adolescents from the Fourth Report on the Diagnosis, Evaluation, and Treatment of High Blood Pressure in Children and Adolescents 2004 [http://www.nhlbi.nih.gov/guidelines/hypertension/ child tbl.pdf).

34. Park MK: Blood pressure tables. Pediatrics 2005, | | 5:826-827.

35. National health and nutrition examination survey: Anthropometry procedure manual. 2000 [http://www.cdc.gov/nchs/data/nhanes/ bm.pdf].

36. Centers for disease control and prevention: About BMI for Children and Teens. 2006 [http://www.cdc.gov/nccdphp/dnpa/obesity/ childhood/defining.htm]

37. Weiss R, Dziura J, Burgert TS, Tamborlane WV, Taksali SE, Yeckel CW, Allen K, Lopes M, Savoye M, Morrison J, et al.: Obesity and the metabolic syndrome in children and adolescents. NEngl J Med 2004, 350:2362-2374.

38. Centro Nacional de Estadísticas de Salud en colaboración con el Centro Nacional para la Prevención de Enfermedades Crónicas y Promoción de Salud (2000): Percentiles del Índice de Masa Corporal por edad. Percentiles del Índice de Masa Corporal por edad. [http://www.cdc.gov/nchs/data/nhanes/growthcharts/Spanishpdf95/ co061023.pdf]. http://www.cdc.gov/nchs/data/nhanes/growthcharts/ Spanishpdf97/co061032.pdf

39. De Fronzo RA, Tobin JD: Glucose clamp technique: a method for quantifying insulin secretion and resistance. American Journal of Physiol 2009.

\section{Pre-publication history}

The pre-publication history for this paper can be accessed here: http://www.biomedcentral.com/1471-2431/9/28/prepub
Publish with Biomed Central and every scientist can read your work free of charge

"BioMed Central will be the most significant development for disseminating the results of biomedical research in our lifetime. "

Sir Paul Nurse, Cancer Research UK

Your research papers will be:

- available free of charge to the entire biomedical community

- peer reviewed and published immediately upon acceptance

- cited in PubMed and archived on PubMed Central

- yours - you keep the copyright
BioMedcentral 